Biocultural e a sustentabilidade local nos agroecossistemas amazônicos de Taquaruçu Grande, Palmas-TO

\begin{tabular}{c|c|c}
\hline ISSN 2525-4812 (versão online) & Revista Terceira \\
$\begin{array}{c}\text { ISSN 2238-7641 (versão impressa) } \\
\text { http://www.revistaterceiramargem.com/ } \\
\text { index.php/terceiramargem/index }\end{array}$ & $\begin{array}{c}\text { Recebido em: 19/6/2019 } \\
\text { Aprovado em: 30/2/2020 }\end{array}$ & $\begin{array}{c}\text { Margem Amazônia } \\
\text { Período de publicação: jul/dez, } 2020\end{array}$ \\
\hline
\end{tabular}

Como citar o artigo:

SANTOS, E. M; FRAXE, T. J. P; ATHAYDE, S. F; SOUZA, L. B. Biocultural e sustentabilidade local nos agroecossistemas amazônicos de Taquaruçu Grande, Palmas - TO. Revista Terceira Margem Amazônia, v. 6, n.15, p. 224-241, 2020. Doi: http://dx.doi.org/10.36882/2525-4812.2020v6i15p224-241.

\title{
BIOCULTURAL E A SUSTENTABILIDADE LOCAL NOS AGROECOSSISTEMAS AMAZÔNICOS DE TAQUARUÇU GRANDE, PALMAS-TO
}

\author{
Eliane Marques dos Santos ${ }^{1}$ \\ Therezinha de Jesus Pinto Fraxe ${ }^{2}$ \\ Simone Ferreira de Athayde ${ }^{3}$ \\ Lucas Barbosa e Souza ${ }^{4}$
}

\begin{abstract}
Resumo: Caracterizar as paisagens amazônicas de Taquaruçu Grande em Palmas-TO, a partir dos elementos bioculturais existentes, seus usos e a perspectiva de sustentabilidade local foram os objetivos deste artigo. A abordagem sistêmica consiste no eixo condutor para a coleta e análise dos dados com uso de observação sistemática, entrevista semiestruturada, registro de imagens e reuniões de grupo focais. Os resultados indicaram paisagens com valor histórico significativo por ainda exibir mosaicos complexos com vegetação em área de unidade de conservação, associadas à agrodiversidade, recursos hídricos e saberes locais. Essa complexidade deve-se à diversidade biocultural resultante de uma persistência histórica local que assinalam a resiliência para esses sistemas e por isso sua sustentabilidade nessas condições de uso.
\end{abstract}

Palavras chaves: Paisagens. Biocultural. Agroecossistemas. Sustentabilidade.

\begin{abstract}
Characterizing the Amazonian landscapes of Taquaruçu Grande in PalmasTO, from the existing biocultural elements, their uses and the perspective of local sustainability was the objectives of this article. The systemic approach consists of the guiding axis for the collection and analysis of data with the use of systematic observation, semi-structured interview, recording of images and focus group meetings. The results

\footnotetext{
${ }^{1}$ Doutora em Ciências do Ambiente e Sustentabilidade na Amazônia (UFAM/PPGCASA). Professora Adjunta da Universidade Federal do Tocantins. E-mail: biologa.eliane@gmail.com

2 Professora Titular do Departamento de Ciências Fundamentais e Desenvolvimento Agrícola. Universidade Federal do Amazonas. E-mail:tecafraxe@uol.com.br

3 Doutora em Ecologia Interdisciplinar (Universidade da Flórida). Professora e Pesquisadora da Universidade da Flórida/EUA. E-mail: simonea@ufl.edu

4 Pós-doutor em Geografia pela Universidade Federal de Goiás (UFG). Professor Associado da Universidade Federal do Tocantins (UFT). E-mail: lbsgeo@mail.uft.edu.br
} 
indicated landscapes with significant historical value because they still show complex mosaics with vegetation in an area of conservation unit, associated with agrodiversity, water resources and local knowledge. This complexity is due to the biocultural diversity resulting from a local historical persistence that signals the resilience to these systems and therefore their sustainability under these conditions of use.

Keywords: Landscapes. Biocultural. Agroecosystems. Sustainability.

\section{INTRODUÇÃO}

Nos agroecossistemas amazônicos de Taquaruçu Grande identificamos o complexo biológico-cultural constituído das diversidades: biológica, cultural, agrícola e paisagística (TOLEDO; BARRERA-BASSOLS, 2015), pois, trata-se de uma área rural do município de Palmas, estado do Tocantins, constituída de produtores familiares com saberes locais associados à agrobiodiversidade.

A temática proposta teve sua escolha assentada na necessidade de se estudar o valor biológico e cultural dessas paisagens rurais, uma vez que as formas de produção reconstroem paisagens correspondentes aos mecanismos socioculturais de produção, característicos dos processos de conservação ambiental, o que permite a existência de arranjos produtivos numa dinâmica constante de modificação das paisagens, nas quais formas de produção são recriadas intergeracionalmente para a manutenção da cultura e da sustentabilidade.

Apesar do conceito de paisagem ser o resultado da relação entre a sociedade e o ambiente, apresentamos o biocultural porque o termo tem como premissa básica que a relação entre os seres humanos e seus ambientes é mediada pela cultura (BERKES, COLDING; FOLK, 2000) e denota a ligação entre biodiversidade e diversidade humana (COCKS, 2006).

O baixo curso da Bacia do Ribeirão Taquaruçu Grande, sistema focal desse estudo, é uma localidade importante da Amazônia Legal, seu território está incluído na Área de Proteção Ambiental Serra do Lajeado (APA), com parcelas das fitofisionomias de domínio do bioma Cerrado.

Engloba um cenário composto por feições fisiográficas interessantes e que, pela condição ecológica que sustentam, propiciam a conservação da flora e da fauna, além de constituir-se em área de recarga de importantes mananciais que abastecem o município de Palmas (SEPLAN, 2004), criada há 29 anos para sediar a capital do Estado do Tocantins. Este artigo caracterizou as paisagens amazônicas de Taquaruçu Grande em 
Palmas-TO, a partir dos elementos bioculturais existentes, seus usos, apontando a perspectiva de sustentabilidade local.

Trata-se de uma localidade de agroecossistemas, com produtores familiares que se relacionam há mais de trinta anos com a terra, essa área rural têm um peculiar envolvimento com os saberes locais, pois, por meio deles se relacionam com o ambiente em que vivem e perfazem o seu cotidiano, a sua rotina, o seu modo de vida - se habitus, ou seja, sistema aberto de disposições, ações e percepções, tecido com o tempo pelos indivíduos em suas experiências sociais (BOURDIEU, 2011).

Construídos ao longo do tempo e do meio em que se encontram, as práticas culturais dos atores sociais demonstram uma autodeterminação desses povos, a partir de uma prática autossustentável e de uma cultura diferenciada. Essas paisagens rurais históricas, especialmente aquelas que apresentam alta heterogeneidade, são muitas vezes relacionadas com práticas tradicionais e fornecem exemplos importantes para a compreensão da diversidade biocultural (AGNOLETTI \& ROTHERHAM, 2015).

\section{METODOLOGIA}

\section{Área do estudo}

A área estudada localiza-se nas margens direita e esquerda da TO 020, próximo ao Ribeirão Taquaruçu Grande, no município de Palmas - TO e possui aproximadamente 4.001,753.795 hectares, está localizada entre os paralelos $10^{\circ} 16^{\prime} 43,04$ " e $10^{\circ} 13$ '58,78"

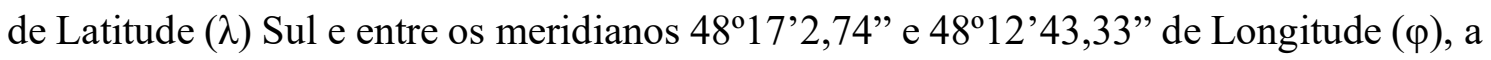
maior parte dessa localidade é de área rural e com predominância de áreas urbanas na parte oeste (Figura 1). 
Figura 1: Área do estudo

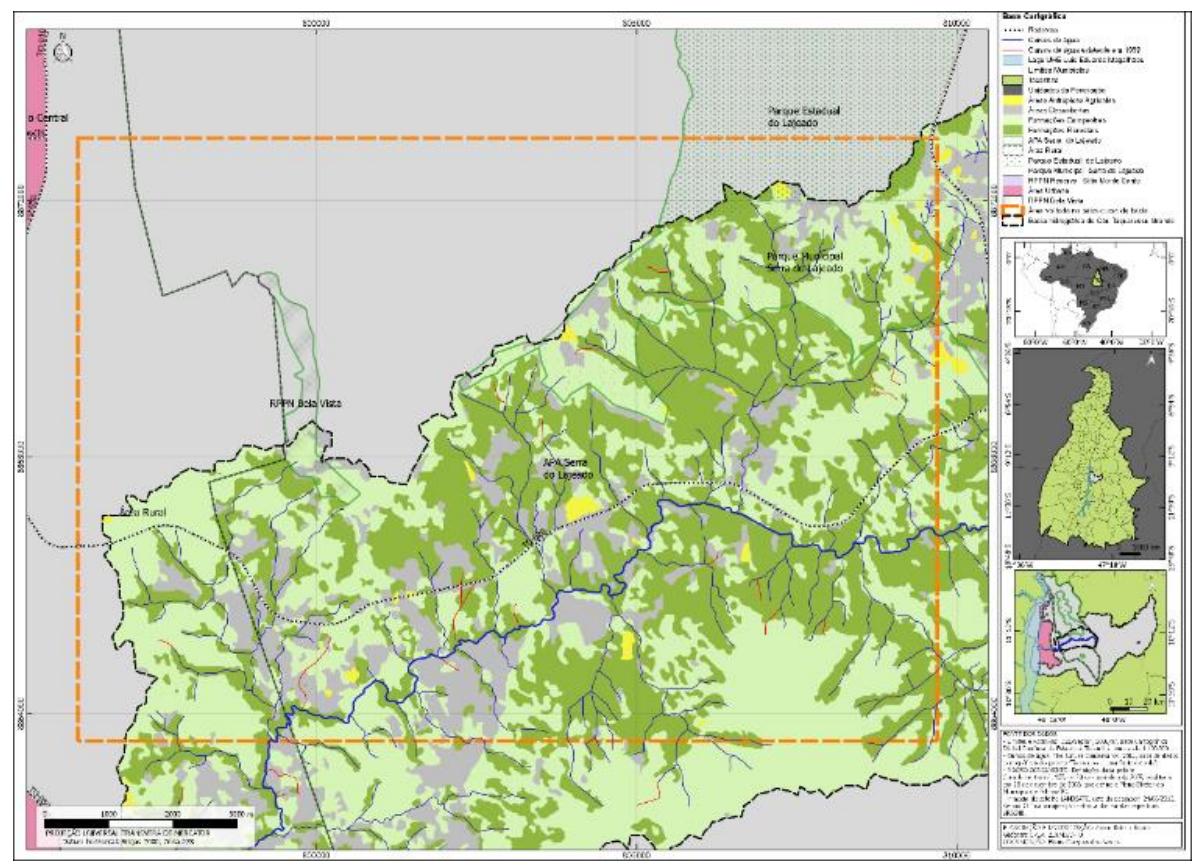

Fonte: Elaboração própria.

\section{Procedimentos Metodológicos}

Este artigo integra uma tese de doutorado do Programa de Ciências do Ambiente e Sustentabilidade da Amazônia e alcançou 12 unidades produtivas familiares, representando a totalidade do universo de moradores residentes na localidade há mais de 30 anos. Essa temporalidade foi critério de seleção dos entrevistados para conhecer a percepção ambiental dos que habitam o lugar antes da criação do município de Palmas TO. Os informantes-chave foram selecionados pela técnica de cadeia informante (PENROD, et al. 2003), a partir dos dados da Associação de agricultores e estão identificados neste trabalho por nome de árvores e denominados atores sociais desse estudo.

A metodologia adotada teve como eixo a abordagem sistêmica buscando compreender as inter-relações existentes no ambiente (MORIN, 1998) e para obtenção dos dados utilizou-se o estudo de casos múltiplos (YIN, 2010) por meio das técnicas de pesquisa: observação sistêmica (MORIN, 2013), entrevista semiestruturada, análise por georreferenciamento, coleta de dados em campo com registro de imagens e Sistema de 
Biocultural e a sustentabilidade local nos agroecossistemas amazônicos de Taquaruçu Grande, Palmas-TO

Posicionamento Global (GPS), análise de conteúdo e a validação dos dados em reuniões de grupo focais.

Os dados coletados em campo foram fotografados, registrados com o GPS, caracterizados segundo ficha de campo adaptada de SANTOS (2009) relacionados às: fitofisionomias da vegetação, ações antrópicas na área, potencial cênico, condições de tráfego, presença ou ausência de corpo hídrico, atividade principal da área.

Para a identificação fitofisionômica foi usada a chave proposta por Ribeiro \& Walter (2008), que utiliza termos regionais e contempla uma maior diversidade de tipos fitofisionômicos, característica marcante do bioma cerrado e da área de domínio da APA Serra do Lajeado.

O tratamento dos dados deu-se por meio da análise de conteúdo (BARDIN, 2011), que envolve um conjunto de técnicas procurando conhecer aquilo que está por trás das palavras sobre as quais se debruça, com auxílio do Programa IRAMUTEQ (CAMARGO E JUSTO, 2013) que apresenta uma análise quanti e qualitativa do agrupamento dos dados.

\section{RESULTADOS E DISCUSSÃO}

As estratégias de usos múltiplos adotada pelos produtores do Baixo curso da Bacia do Ribeirão Taquaruçu Grande, influenciada pelo habitus (BORDIEU, 2011), caracterizam-se por um sistema integrado de práticas produtivas e se expressa no espaço como uma paisagem de mosaicos complexos de uso da terra, com um alto nível de diversidade de habitat produzido pela aplicação de diferentes regimes de gestão, que veio a atender os fatores econômicos, sociais e ambientais da sociedade em questão. A maior diversificação estrutural e funcional dos mosaicos produtivos favorece em princípio, a resistência e a resiliência dos sistemas que passaram por intervenções (TOLEDO \& BARRERA-BASSOLS, 2015).

Este artigo apresenta a diversificação estrutural dos mosaicos produtivos por meio dos componentes bioculturais das paisagens com áreas de: sistema de produção, áreas de vegetação (formações campestres, formações florestais, formações savânicas), áreas com fins urbanos e corpos hídricos, ocorrendo no espaço como mosaicos de paisagens complexas e seus elementos bioculturais representados na Figura 2. 
Biocultural e a sustentabilidade local nos agroecossistemas amazônicos de Taquaruçu Grande, Palmas-TO

Figura 2: Mosaico da paisagem de Taquaruçu Grande

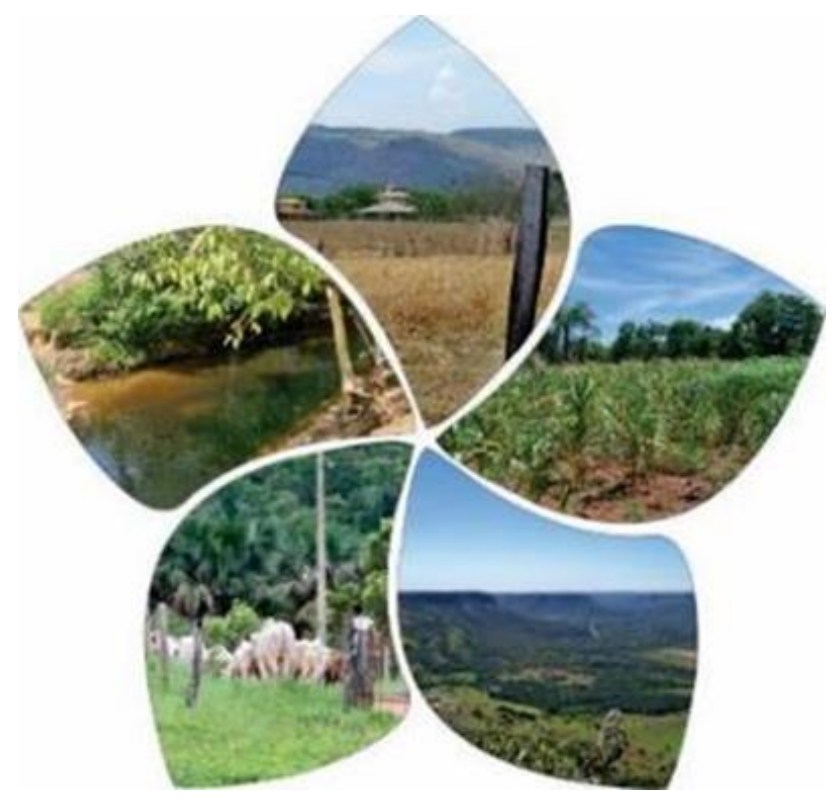

Fotos: SANTOS (2017)

Estas paisagens são resultantes da interação humano e ambiente, fruto das relações socioculturais que revelam a história de um povo e de uma época, permeado pelos valores morais, éticos, religiosos, políticos, etc., através dos quais constroem, reconstroem os seus lugares e constituem os elementos bioculturais.

As relações do ser humano e o agroecossistema aqui estudadas foram submetidas à análise lexical (Figura 3) cujo agrupamento de palavras-chaves destacam o que foi mais citado e o quantitativo nas falas dos atores sociais.

Figura 3: Nuvem de palavras

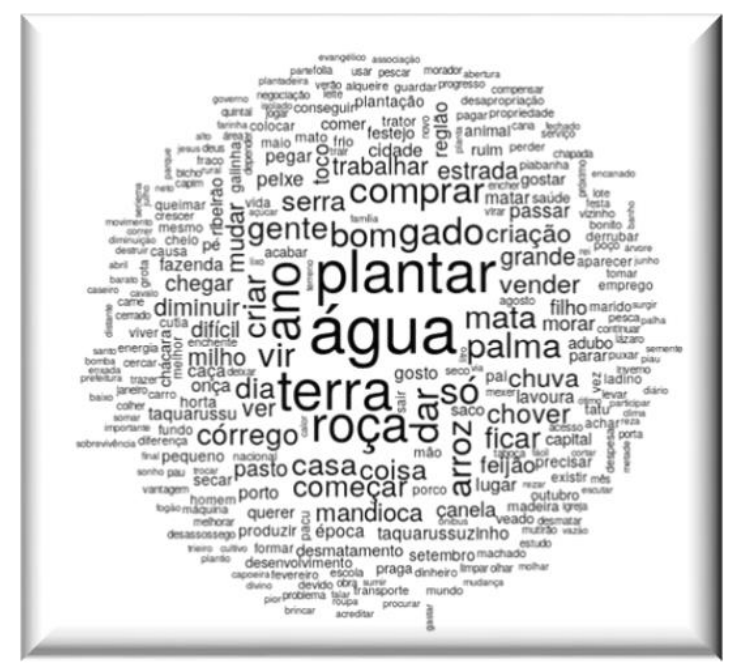

Fonte: Pesquisa de campo, 2017. 
Biocultural e a sustentabilidade local nos agroecossistemas amazônicos de Taquaruçu Grande, Palmas-TO

Plantar (33), água (30), roça (20), terra (16), chamam atenção para necessidades básicas do cotidiano, refletidas até hoje nas ações de produção familiar e habitus das famílias. Esses dados foram submetidos à análise de similitude (Figura 4), na qual visualiza-se as indicações de conexidade entre os elementos constitutivos das falas dos entrevistados.

Figura 4: Análise de Similitude

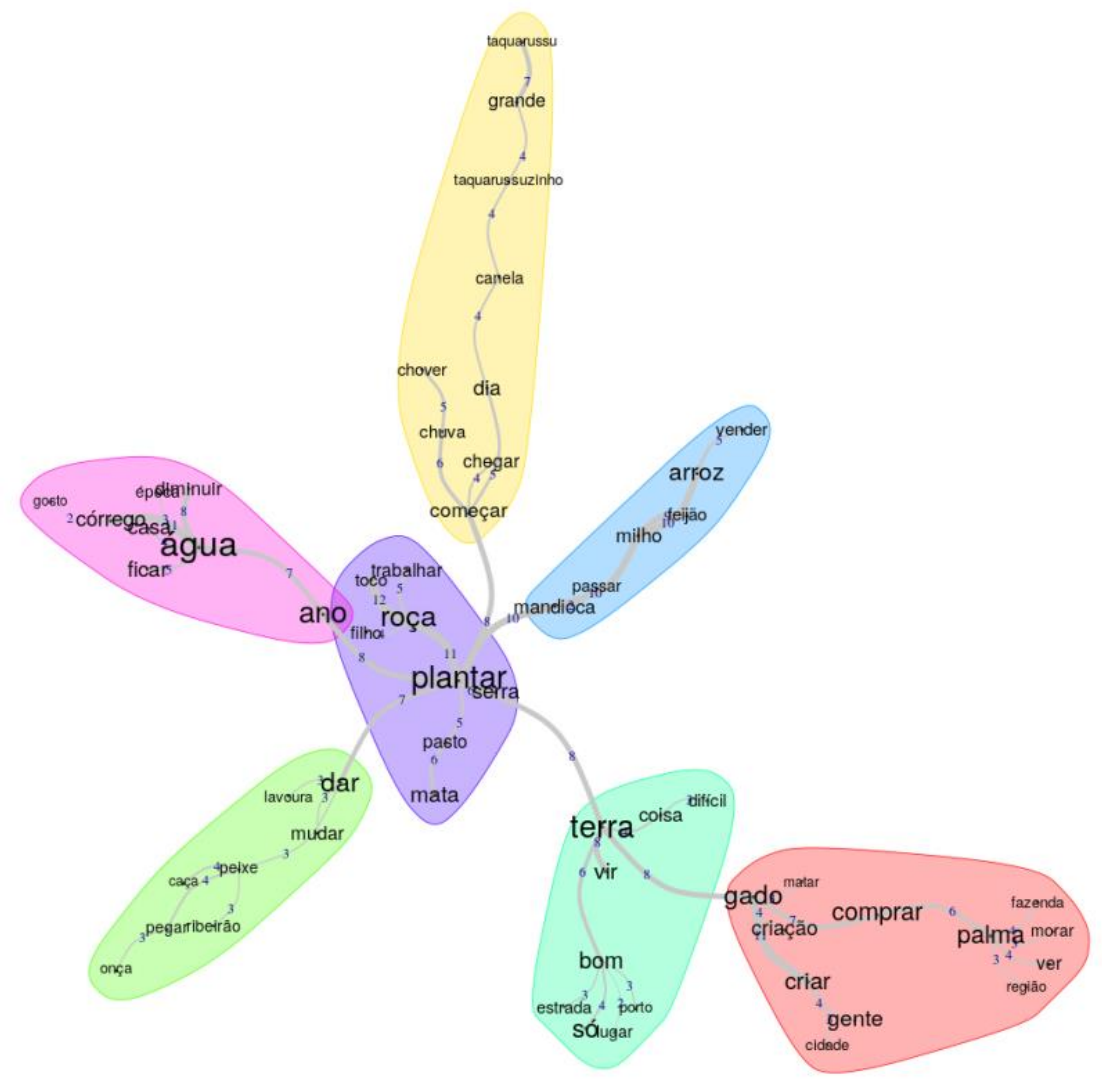

Fonte: Pesquisa de campo, 2017.

Nessa análise destacam-se no corpus textual as palavras: plantar, água, roça, terra e gado em negrito que aparecem com uma frequência bastante alta, confirmando a nuvem de palavras. Destaca-se que o fazer cotidiano de plantar conecta todas as demais palavras que se relacionam a ela e esta ação foi mencionada nas falas como a principal atividade desenvolvida para a sobrevivência. 
Biocultural e a sustentabilidade local nos agroecossistemas amazônicos de Taquaruçu Grande, Palmas-TO

Em sua maioria esses moradores residentes há mais de 30 anos no local, eram homens e mulheres em busca de melhores condições de vida e sobrevivência que encontraram na paisagem dos vales de Taquaruçu Grande, a auto sustentação, por ser um sistema ambiental altamente diversificado, no qual havia uma biodiversidade para subsidiar a sobrevivência.

Como aponta a verbalização transcrita: “Antes, derrubava tudo para plantar. Era roça de toco nas margens dos ribeirões, cercava de madeira por causa das criações, não tinha arame. Todo ano era num local diferente, porque só dá bom no primeiro ano (Sra. Laranjeira, 72 anos)".

$\mathrm{Na}$ área estudada a agricultura é constituída de pequenos produtores que desenvolvem atividades fora do circuito comercial, que se caracterizam por apresentar um baixo nível de renda e precárias condições de vida. Entre os principais produtos agrícolas destacam-se: feijão, mandioca, milho e hortaliças, apesar da topografia acidentada e solos pobres em micro e macronutrientes. Essas estratégias cognitivas e de ação (MORIN, 2011), sobre agrodiversidade expressas na organização dos agroecossistemas dialoga com o saber local demonstrando-as no habitus dos produtores deste estudo.

O sistema de produção do baixo curso da Bacia do Ribeirão Taquaruçu Grande tem como base prática as agroflorestas caracterizadas pelo manejo de terras numa integração entre árvores e/ou animais e/ou cultivos agrícolas. Os fatores de produção são combinados com técnicas convencionais aliadas a tecnologias atuais que regem o sistema produtivo.

Considerando a história desses sistemas, essa área apresentava anteriormente cobertura vegetal nativa, como aponta a descrição: “Casas poucas e muito cerrado. Tudo era cerrado fechado. As casas eram longe uma da outra, casa de palha e menos vizinho (Faveira de Bolota, 55 anos)". Algumas destas áreas foram desmatadas para perpetrar a roça de toco, cultivo de arroz, milho, mandioca e feijão. Como não havia o aproveitamento do solo, todos os anos essas roças eram transferidas para outro local.

Atualmente boa parte apresenta cobertura vegetal, pois, utilizam áreas já desmatadas para os rebanhos de caprinos, suínos, bovinos e, principalmente, para a cultura de milho, feijão e mandioca. Essas alterações foram influenciadas pelas políticas públicas e ações de fiscalização dos órgãos governamentais, provocando mudanças nas práticas produtivas familiares e gerando a diminuição destas. 
As atividades nos agroecossistemas têm a produção assentada na mão-de-obra familiar, com a participação dos filhos e, geralmente algum outro agregado familiar, como genro, noras, tios e primos. As mulheres participam do planejamento, das atividades e ajudam a realizar a maioria delas. A atuação da mulher na família é fundamental para a manutenção dos agroecossistemas, pois está presente no trabalho de roça, nos mutirões, no cultivo das hortas e na organização do trabalho. O trabalho doméstico é realizado pela mãe e filhas, as tarefas mais pesadas, como as ligadas à pecuária, cabem aos homens.

As áreas de produção são planejadas de acordo com a localização geográfica dos terrenos e de acordo com o período de chuvas. Os componentes do sistema de produção são constituídos de: roças, quintais agroflorestais, capoeira, extrativismo vegetal e criação de animais.

Os principais sistemas de produção em roças e quintais das unidades produtivas familiares são: a agricultura de produtos de ciclos curto (feijão, milho, hortaliças e legumes), médio (banana prata), longo (mandioca) e a criação de animais. Esses produtos são para o consumo familiar, o que amplia a diversificação das espécies cultivadas, corresponde no aumento da produtividade ecológica e contribui para a resiliência do sistema. A sustentabilidade e resiliência são alcançadas por meio de ações de manutenção da diversidade e complexidade do sistema ambiental (ALTIERI, 2012).

As unidades paisagísticas produtivas são constituídas pelas fitofisionomias do cerrado nelas encontram-se: A) Cultivo de hortaliças para comercialização, produzidas para atender a demanda do município de Palmas e constitui uma dinâmica diferente da produção familiar; B) Campos agrícolas, destinados ao cultivo de agrobiodiversidade com uso de consórcio para auto sustentação da unidade produtiva familiar; C e D) Quintais agroflorestais, são áreas pequenas que possuem cultivos heterogêneos e árvores frutíferas e E e F) Pastagem, destinadas à criação de gados (Figura 5). 
Biocultural e a sustentabilidade local nos agroecossistemas amazônicos de Taquaruçu Grande, Palmas-TO

Figura 5: Unidades paisagísticas produtivas: A) Cultivo de hortaliças comercializáveis; B) Campo agrícola C e D) Quintais agroflorestais; E e F) Pastagem.
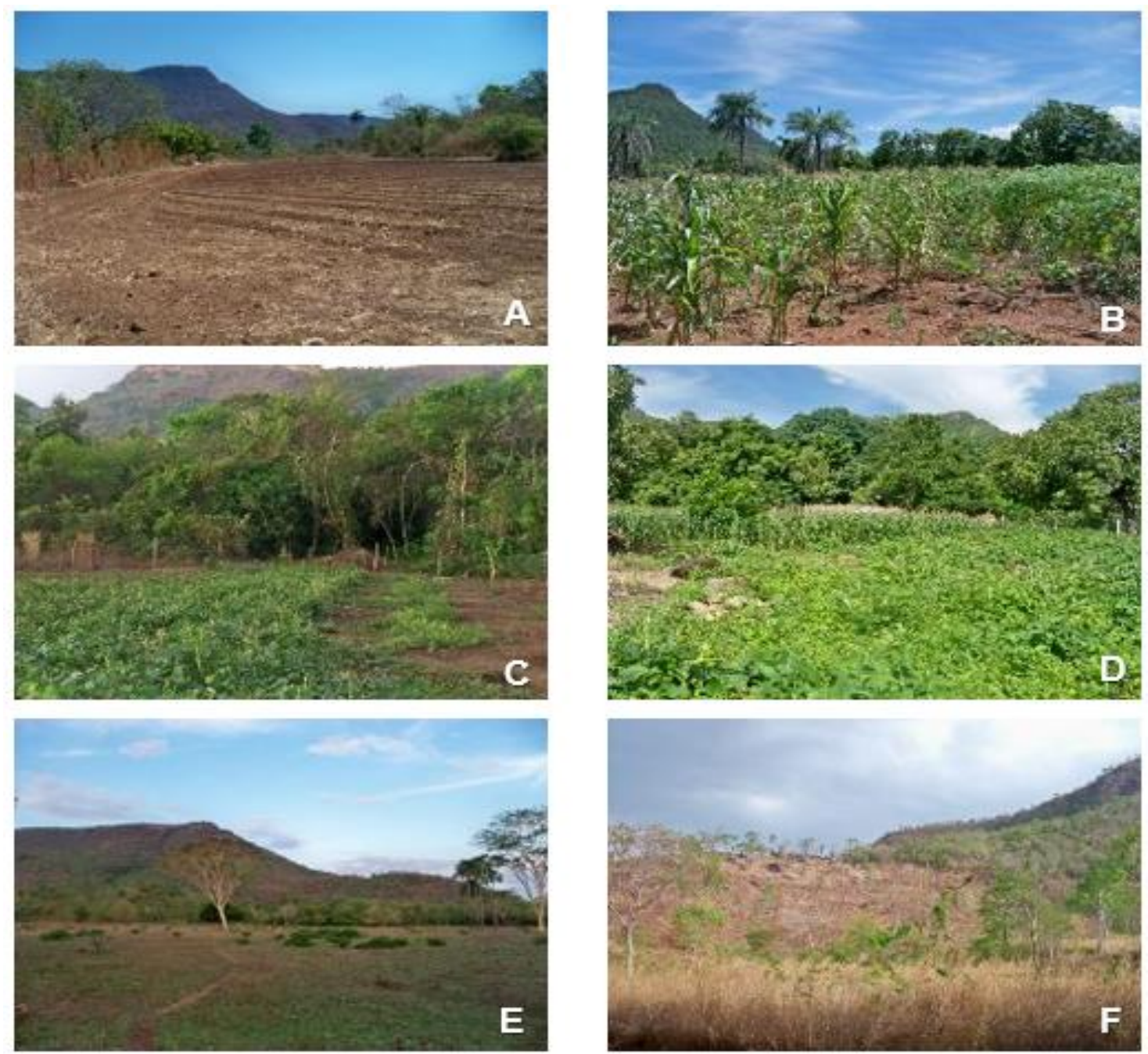

Fotos: SANTOS (2016).

A permanência da produção agrícola familiar é um indicador da resiliência biocultural desse sistema, que apesar de sofrer alterações mediante a criação do município de Palmas-TO, alterando o habitus local, desenvolveu estratégias de uso da terra para continuar essa prática cultural, mesmo em menor quantidade. Sendo a memória biocultural (TOLEDO \& BARRERA-BASSOLS, 2015) e a circularidade de saberes, fios condutores do conhecimento para a continuidade dessa cultura.

Os quintais agroflorestais representam uma unidade agrícola de uso tradicional do solo, sua principal finalidade é a produção de alimento para complementação da dieta familiar, além do potencial de sustentabilidade ecológica, os quintais são considerados sistemas alternativos de complementação da demanda alimentar (NODA et al, 2007). Os 
quintais estão organizados espacialmente em cultivos de espécies arbóreas, arbustivas e herbáceas de valoração utilitária. Uma alta diversidade de espécies, com múltiplas finalidades, é cultivada nos quintais, tais como plantas usadas para sombra, ornamentação, alimentação, medicina, canteiros para hortas e outros (Figura 6).

Figura 6: Quintais agroflorestais.

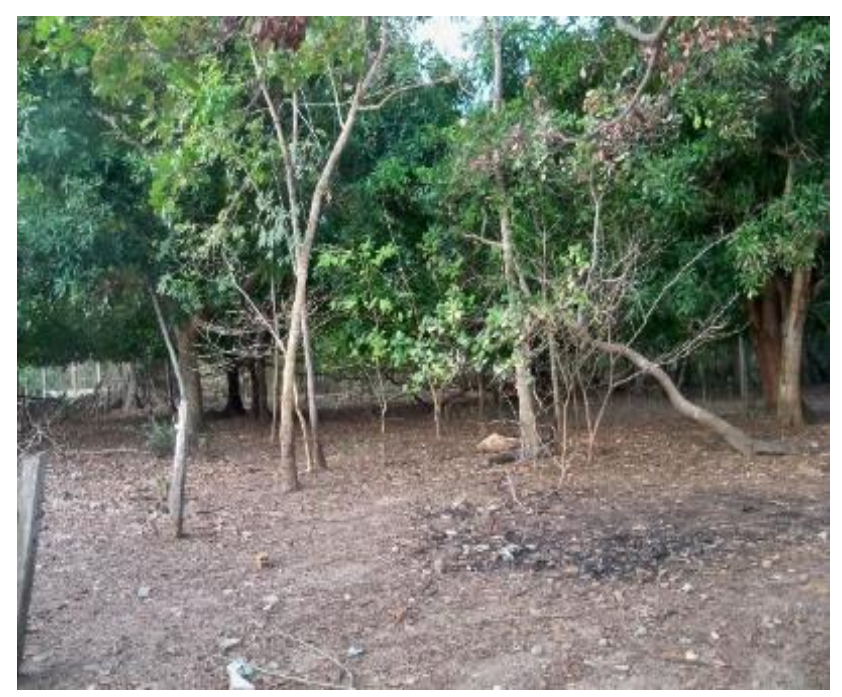

Fonte: Pesquisa de campo, 2016

A abordagem biocultural não deve se concentrar apenas em preservar áreas selvagens, mas também, na conservação da biodiversidade local, valorizando as paisagens agrícolas. Desta forma, os valores bioculturais contribuem para a criação de paisagens diversificadas que transcendem a dicotomia aceita entre áreas selvagens e campos cultivados. Dentro de tais paisagens, as pessoas locais podem propositadamente conservar a biodiversidade que elas valorizam (COCKS, 2006).

As roças são paisagens cultivadas anualmente em regime de rotação e consórcios, com vários arranjos paisagísticos, nas quais a diversidade biológica pode ser verificada, ocorrendo variedades intra e interespécies. Para PERONI (2002) a roça representa a continuidade e o dinamismo do conhecimento acumulado e não apenas um repertório de diversidade biológica.

O manejo agrícola familiar das roças nas unidades produtivas familiares constitui-se mantenedor de uma agrobiodiversidade, baseada no cultivo de mandioca, milho, feijão, cana-de-açúcar, hortaliças, legumes (Figura 7) e outros, encontradas nas roças e nos quintais, sendo componentes indispensáveis nas refeições das unidades familiares e na criação de animais. 
Biocultural e a sustentabilidade local nos agroecossistemas amazônicos de Taquaruçu Grande, Palmas-TO

Figura 7: Roças: milho, feijão e abóbora.

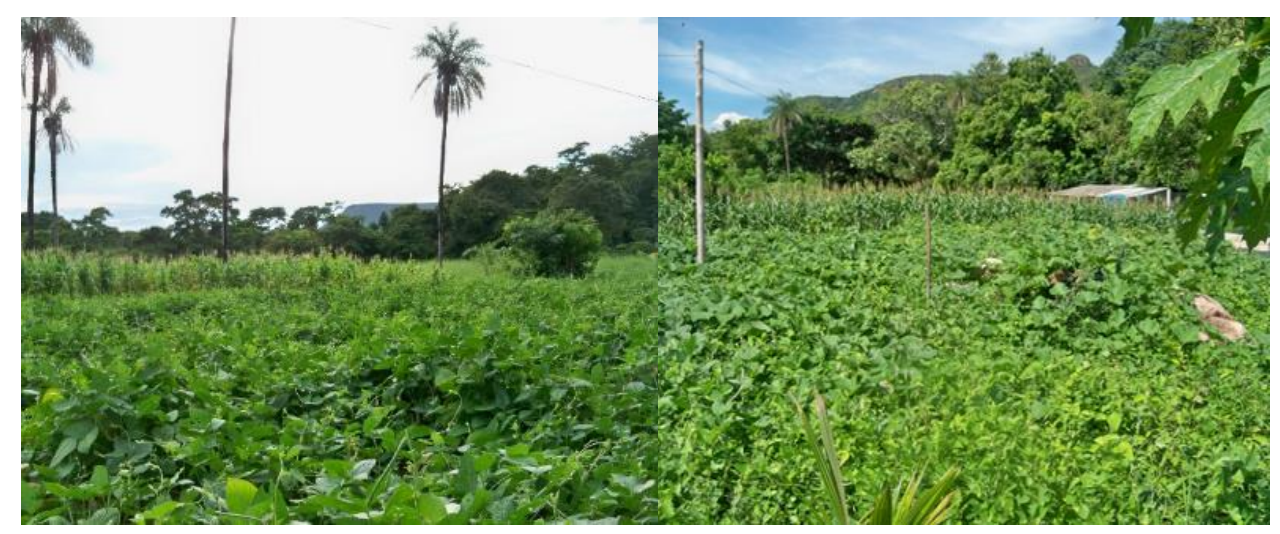

Fonte: Pesquisa de campo, 2016.

As áreas deixadas em descanso para recuperação após alguns anos de produção são denominadas como pousio. Esta prática é denominada de descanso, atualmente se dá para obedecer à conservação dos recursos ambientais proposto pela Legislação ambiental. Quando questionamos os produtores sobre o pousio das terras, identificamos que na época de roça de toco não era utilizado: "Eu acompanhava as experiencias do meu pai, não fazia descanso plantava todo ano. De três anos vai ficando fraca, tirando a mandioca planta feijão e melancia (Sr. Buritizeiro, 56 anos) '”.

Ao investigarmos sobre o extrativismo vegetal, nos revelaram fatores ligados às roças de toco: "Cercava a roça de madeira, a geometria era o lugar que ficava melhor, aproveitavam as margens dos córregos, onde a terra era mais produtiva. Eles não tinha a preocupação com a beirada do córrego, era pra facilitar, não tiravam todas as árvores grossas (Sra. Ingazeiro, 60 anos)”.

Percebe-se nos relatos a mudança de atitudes e hábitos anteriores de exploração devido a influência das ações dos órgãos de fiscalização: "Hoje tem ainda madeira, mas é pouca. Naquela época eles derrubavam tudo até no córrego. Por causa das exigências do Naturatins e muitos denunciam, pararam (Sr. Bacabeiro, 56 anos) '”. Todavia, não foi identificado no conteúdo das falas uma percepção ambiental de conservação dos recursos ambientais como uma preocupação ou hábito dos moradores. Um produto do extrativismo vegetal bastante explorado é a polpa do buriti (Mauritia flexuosa), praticada por todas as famílias, como fonte de renda para as mulheres por meio da venda da polpa e do doce. 
Biocultural e a sustentabilidade local nos agroecossistemas amazônicos de Taquaruçu Grande, Palmas-TO

As formas de produção alocadas na produção familiar utilizam animais de pequeno porte (aves, suínos e caprinos), alimentados com restos de alimentos das refeições familiares, milho, frutas caídas no chão, mandioca e seus processados. A criação destes animais é doméstica e é realizada nos quintais agroflorestais como uma alternativa alimentar e por fazer parte dos hábitos na dieta alimentar: "Criava porco, galinha, bode, ovelha, jumento, cachorro e hoje tem galinha, porco e gado pra comer no natal (Sr. Cajueiro, 53 anos)"”.

A produção bovina constitui a principal atividade econômica das propriedades, foi bastante reduzida em consequência da diminuição das terras: "O gado deixou de criar porque a terra ficou pouca (Sra. Laranjeira, 72 anos)", assim a atividade na percepção dos produtores tem um caráter de poupança para as necessidades das famílias e complementação de renda familiar: "Eu crio o gado porque é um renda a mais (Sr. Jamelão, 63 anos)”'.

A diversidade de produtos originados na produção familiar dos agroecossistemas de Taquaruçu Grande constitui um dos atributos do sistema que garante a sua sustentabilidade nesses espaços, pois, as transformações sofridas no sistema propiciaram a adaptabilidade a estas perturbações e a manutenção das atividades ditadas pela cultura local.

A paisagem do baixo curso da Bacia de Taquaruçu Grande é marcada pelas áreas de vegetação, a linha do horizonte está sempre delineada na sinuosidade da serra, porém, já se observa um crescimento na urbanização nas últimas décadas após a criação do município de Palmas-TO. O potencial cênico identificado chama a atenção pela biodiversidade, na maioria dos pontos é constituído pela combinação de vegetação, aves, corpo hídrico, mas, principalmente pela Serra do Lajeado, que influenciados por uma gama de variáveis definem as belas e admiráveis paisagens existentes na bacia estudada.

A paisagem possui variações em suas características, sendo perceptíveis pelas suas fisionomias, apresentando-se desde áreas com predominância arbórea, passando por áreas mescladas com árvore, arbustos e herbáceas, até as formações de estrato graminoso predominante, classificadas segundo RIBEIRO \& WALTER (2008) como formações campestres, savânicas e florestais (Figura 8). 
Figura 8: Formações vegetais (da esquerda à direita): (A) Campestre, (B) Savânica e (C) Florestal.
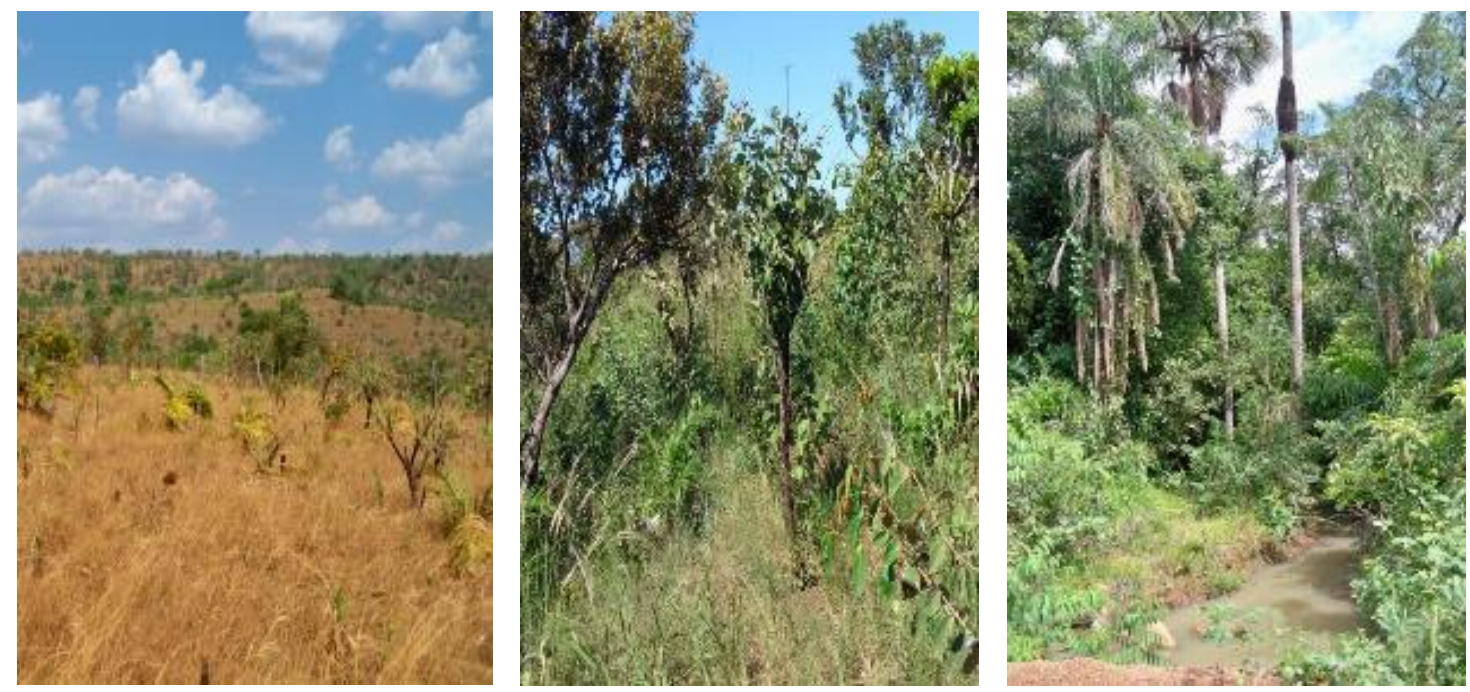

Fonte: Pesquisa de campo, 2016.

As paisagens campestres campo sujo e campo rupestre foram as que mais sofreram perturbações na localidade nos últimos anos, devido ao manejo baseado no fogo. O campo sujo apresentou uma vegetação escassa de espécies arbórea e arbustiva, e o campo rupestre apresentou-se com forma do tipo herbácea, com predomínios de espécies das famílias Poaceae e Cyperaceae.

Do conjunto fitofisionômico apresentado para a formação savânica ocorrem nas áreas: cerrado típico, veredas, palmeiral e o cerrado denso, nestas áreas muitas fitofisionomias já deram espaços às atividades de uso agrícolas, pastagens cultivadas e área de uso urbano.

A vegetação do cerrado típico apresentou-se com árvores e arbustos de pequeno porte e tortuosas com ramificações irregulares e retorcidas devido, principalmente, a ação do fogo. A fitofisionomia vereda e o palmeiral encontrada na área apresentou-se apenas como um pequeno fragmento e com a presença marcante da espécie Mauritia flexuosa, conhecido popularmente como buriti.

A localidade de cerrados é muito heterogênea, com ecossistemas estáveis, resistentes e sistemas extremamente sensíveis à ação antrópica. As áreas de vegetação com fitofisionomias do cerrado observadas, contemplam variadas coberturas e boa parte destas fitofisionomias apresentam-se antropizadas, os solos expostos aparecem em toda a Bacia, principalmente associados à urbanização. 
Biocultural e a sustentabilidade local nos agroecossistemas amazônicos de Taquaruçu Grande, Palmas-TO

Ressalta-se para as áreas de florestas observadas na Serra do Lajeado extensas áreas conservadas que se apresentam como habitat propício à diversidade biológica, com vegetação alternando entre áreas com árvores mais baixas, densas e árvores de até $25 \mathrm{~m}$.

Após a criação de Palmas, a localidade tem sido marcada por profundas modificações sociais, econômicas e principalmente ambientais, entre elas a retirada da vegetação denominadas por eles como mata: “Antes, as casas eram poucas e muito cerrado. Tudo era cerrado fechado. As casas eram longe uma da outra, casa de palha e menos vizinho (Sra. Faveira de Bolota, 55 anos)”.

Nesse sentido, a forma com que as populações rurais usam a floresta é reflexo da relação entre fatores culturais, socioeconômicos e os recursos bióticos e abióticos daquela paisagem, todos esses fatores se inter-relacionam e se transformam ao longo do tempo (AGNOLETTI \& ROTHERHAM, 2015).

Os atores sociais do sistema focal manifestaram uma preocupação em relação à conservação de matas associadas aos corpos hídricos: "Água só tem se tiver mata, se desmatar seca tudo, é preocupante. A riqueza maior é a água e a mata temos que conscientizar que temos que plantar, pois o calor tá demais. Da maneira que foi desmatado a mata foi sumindo. Conscientizar pra não desmatar mais, se possível plantar (Sra. Ingazeiro, 60 anos)".

A área do estudo apresenta corpo hídrico sem a presença de mata ciliar, devido ao desmatamento e ocupação urbana, a sua preservação e recuperação são de suma importância, tornando-se fundamental o uso sustentável destes ambientes (RODRIGUES \& GANDOLFI, 2004). Em outros locais apresentaram corpo hídrico, porém, perenes, exibindo mata de galeria com muitos sinais de antropização. A formação florestal associada a cursos de água se encontra sobre forte antropização com ocorrência frequente de desmatamento, queimadas e ocupações humana.

As áreas do sistema de produção e as áreas de vegetação se encontram em constante luta por uma harmonia para sobrevivência de ambas, sendo influenciadas pelos saberes locais utilizados na intenção de promover uma coexistência harmônica entre homem e ambiente, uma vez que essa área integra a Área de Proteção Ambiental da Serra do Lajeado, onde está o Ribeirão Taquaruçu Grande principal fonte de abastecimento populacional de Palmas.

Sobre o córrego principal, o Ribeirão Taquaruçu Grande foi relatado que: “ $O$ ribeirão era fundo, hoje tem pouca água, tem menos de um quarto de água. De uns dez. 
Biocultural e a sustentabilidade local nos agroecossistemas amazônicos de Taquaruçu Grande, Palmas-TO

anos pra cá, diminuiu muito, ele era coberto de mata de um lado e outro. A lesão vai dentro (Sr. Goiabeira, 87 anos)”.

Apesar da importância dada aos corpos hídricos, estes estão antropizados e são utilizados sem um plano de gestão de usos da água. Os principais impactos dizem respeito à retirada da vegetação ciliar, uso desordenado para lazer, assoreamento, lixo, exploração da água na horticultura e dessendentação de animais.

As paisagens estudadas têm resistido à passagem do tempo e são exemplos de agroecossistemas resilientes, por manterem como atributos a percepção da terra como reprodução social e bem viver e a circularidade de saberes entre as gerações, embora com redução das práticas culturais pela influência da urbanização.

\section{CONSIDERAÇÕES FINAIS}

A paisagem analisada é resultante da combinação dinâmica de elementos físicos, biológicos, sociais e culturais, os quais reagem dialeticamente entre si, como um todo de paisagens bioculturais. Elas têm valor histórico significativo por ainda exibir mosaicos complexos de paisagens com vegetação em área de unidade de conservação, associadas à agrodiversidade, recursos hídricos e saberes locais, sendo mantidas as práticas culturais relacionadas ao manejo agrícola e a criação de animais no sistema de produção local. Uma vez que o sistema de uso da terra é caracterizado por uma longa persistência histórica e uma forte conexão com os sistemas sociais e ambientais locais que o produzem.

Os processos produtivos e os saberes locais que levaram à construção dessas paisagens são responsáveis pela manutenção da diversidade dos ambientais locais. A estrutura complexa do mosaico de paisagem nessas áreas é uma ilustração exemplar da diversidade biocultural, que assinala a resiliência para esses sistemas e por isso sua sustentabilidade nessas condições de uso.

Neste cenário biocultural, além das condições ecológicas citadas, os resultados apontam que os produtores familiares possuem uma continuidade dos laços afetivos com o local (topofilia) e percebem a terra como elemento de continuidade do seu habitus. Ressalta-se a valoração dada à manutenção dos costumes e da herança cultural deixada por seus antepassados, que são característicos da intrínseca relação com o ambiente em que vivem, constituindo um legado de saberes e práticas culturais ameaçados de extinção 
Biocultural e a sustentabilidade local nos agroecossistemas amazônicos de Taquaruçu Grande, Palmas-TO

pela não continuidade, devido aos aspectos sociais, econômicos e culturais impostos pela urbanização.

Esses aspectos da dinâmica da produção agrícola familiar nesta área contribuíram para a sustentabilidade local, uma vez que em outras áreas dessa Bacia prevalece um aumento do agronegócio, sugerindo outras condições socioambientais aqui não avaliadas.

Aceitando que as paisagens do baixo curso da Bacia de Taquaruçu Grande não possam ser protegidas na sua totalidade, considerando que integram uma UC de uso parcial, precisam ser reconhecidas a uma escala nacional dentro de uma abordagem de planejamento integrado que incorpore desenvolvimento sociocultural, econômico e ambiental. Tal planejamento paisagístico integrado à sustentabilidade local promoverá a conservação ambiental, produção agrícola e o patrimônio cultural que se encontram no coração dessas paisagens.

\section{AGRADECIMENTOS}

Á Coordenação de Aperfeiçoamento de Pessoal de Nível Superior pelo financiamento do estudo. Aos sujeitos envolvidos nesse estudo por compartilharem seus saberes e nos permitir conhecer o biocultural.

\section{REFERÊNCIAS}

AGNOLETTI, M.; ROTHERHAM, I. D. Landscape and biocultural diversity. Biodivers Conserv, 24, 3155-3165, 2015. doi 10.1007/s10531-015-1003-8.

ALTIERI, M. Agroecologia: bases científicas para uma agricultura sustentável. 3 ed. São Paulo - Rio de Janeiro: Expressão Popular - AS-PTA, 2012.

BARDIN, L. Análise de conteúdo. São Paulo: Edições 70, 2011.

BOURDIEU, P. A Economia das trocas simbólicas. 5. ed., São Paulo: Perspectiva, 2011.

CAMARGO, B. V.; JUSTO, A. M. Tutorial para uso do software IRAMUTEQ (Interface de R pour les Analyses Multidimensionnelles de Textes et de Questionnaires), [s.d], p.1-32, 2013. Disponível em: http://www.iramuteq.org/documentation/fichiers/tutoriel-en-portugais

COCKS, M. Biocultural Diversity: moving beyond the realm of 'Indigenous' and 'Local' People. Human Ecology, 34(2):185-200, April 2006. doi: 10.1007/s10745-006-90135.

MORIN, E. Ciência com consciência. 2 ed. Rio de Janeiro: Bertrand, 1998. 
Biocultural e a sustentabilidade local nos agroecossistemas amazônicos de Taquaruçu Grande, Palmas-TO

O método II: a vida da vida. Tradução LOBO, M. Porto Alegre: Sulina,

2011.

O método 1: a natureza da natureza. 3 ed. Porto Alegre: Editora Sulina, 2013.

NODA, S. N. et al. Contexto Socioeconômico da agricultura familiar nas várzeas da Amazônica. In: Noda, S. N. (org.) Agricultura familiar na Amazônia das Águas. Manaus: Editora UFAM, 2007.

PENROD, J. et al. A discussion of chain referral as a method of sampling hard-to-reach populations. Journal of Transcultural nursing, 14(2), april, 2003. doi: $10.1177 / 1043659602250614$

PERONI, N. Coleta e análise de dados quantitativos em etnobiologia: introdução ao uso de métodos multivariados. In: Amorozo, M. C. M.; Ming, L. G.; Silva, S. P. (Eds.). Métodos de coleta e análise de dados em etnobiologia, etnoecologia e disciplinas correlatas. Rio Claro: UNESP/SBEE/CNPq, 2002. p. 155-180.

RIBEIRO, J.F. E WALTER, B.M.T. As principais fitofisionomias do bioma Cerrado. In: Sano, S.M., Almeida, S.P. e Ribeiro, J.F. (Orgs.). Cerrado: ecologia e flora. Brasília: Embrapa Cerrados/Embrapa Informação Tecnológica. v.1. 2008.

RODRIGUES, R. R.; Gandolfi, S. Conceitos, Tendências e Ações para a Recuperação de Florestas Ciliares in: Rodrigues, R.R., Leitão-Filho, H. F. (Orgs.). Matas Ciliares: Conservação e Recuperação, Edusp/Fapesp, São Paulo, 2004.

SANTOS, E. M; ADORNO, L. F.; MORAIS, P. B. Indicadores de sustentabilidade para o ecoturismo como subsídio à implantação de estrada-parque no Jalapão - TO. Revista Brasileira de Ecoturismo. São Paulo, v. 3, n. 2, 2010, p. 249-272.

SEPLAN - Secretaria do Planejamento. Plano de Manejo Parque Estadual do Lajeado/ SEPLAN/ DBO Engenharia. Naturatins: Goiânia, 2004. Disponível em: www.gesto.to.gov.br/site_media/upload/gestao/.../PEL_Plano_de_Manejo_2005.pdf

TOLEDO, V. M.; BARRERA-BASSOLS, N. A Memória Biocultural: A importância ecológica das sabedorias tradicionais. São Paulo: Expressão Popular, 2015.

TUAN, Y. Topofilia: um estudo da percepção, atitudes e valores do meio ambiente. São Paulo: Difel, 1980.

YIN, R. K. Estudo de caso: planejamento e métodos. 2 ed. Porto Alegre: Bookman, 2010 . 